\title{
Mixed Nucleotide Abnormalities
}

National Cancer Institute

\section{Source}

National Cancer Institute. Mixed Nucleotide Abnormalities. NCI Thesaurus. Code C45658.

Point mutations at various locations in a DNA sequence from eukaryotic or prokaryotic organisms in which a nucleotide substitution, deletion or insertion has occurred at each affected site. These abnormalities can be either heritable or occur somatically. 